\title{
Oral Mucositis Rating Scale
}

National Cancer Institute

\section{Source}

National Cancer Institute. Oral Mucositis Rating Scale. NCI Thesaurus. Code C100096.

A research tool used to assess inflammation in the mouth and classification of oral changes after bone marrow transplant and chronic graft versus host disease. 